\title{
Regulation and gender equality and non-discrimination of women in top management positions in Ghana
}

\author{
Olivia Anku-Tsede* and Cynthia Gadegbeku
}

Department of Organization and Human Resource Management, University of Ghana Business School, Legon, Ghana.

Received 26 August,2013; Accepted 13 June, 2014

\begin{abstract}
The engagement of more women at top level management positions in both public and private institutions has increasingly been attracting interest amongst the general public, academia and policymakers; especially given the seemingly increasing participation of females in the labour market. In spite of the many campaigns for the inclusion of women at top level management, it appears the proportion of women to men in senior management positions has not been encouraging. The aim of the study was to gain insight into the impact of international conventions and local laws on gender equality, inclusion and non-discrimination of women at top level management in Ghana. A structured questionnaire was used to collect data from $\mathbf{1 6 0}$ workers. The results of the study revealed that despite the number of conferences, conventions, policies and legislations enacted to ensure the non-discrimination, inclusion and equal representation of women at all levels in both public and private institutions, most institutions do not adhere to these enshrined principles. Again, the study showed that the appointment and selection of persons to such top level management positions is often influenced by factors unassociated with qualification, experience or knowledge in Ghana. It is recommended that institutions should be required by law to comply with the provisions of the various conventions and policies through concrete and deliberate actions in order to provide an enabling environment for women to occupy top management positions in Ghana. The study further suggested that affirmative actions be embarked upon with other considerations such as qualification, experience and knowledge.
\end{abstract}

Key words: Regulations, gender equality, non-discrimination, women in managerial position, Ghana.

\section{INTRODUCTION}

In the past, cultural factors determined gender roles in Africa. There were three basic roles - reproductive, productive and community management roles (Tuyizere, 2007). Men were perceived as playing the productive and community management (leadership) roles while women played the reproductive role and cared for the general welfare of the family. With an increase in girl-child education, globalisation, adulteration of cultures, govern- mental laws and policies, and current economic conditions, the role of women seems to have changed. A lot of women have found their way into private and public sector occupations with some of them in managerial positions. In the first place, working outside the home for an income was solely the preserve of men. Now women are working in this sector and are rising through the ranks to also assume leadership or managerial roles that were

*C orresp onding a uthor. E-ma il: oa nkutsede@ug.edu.gh; Tel: (233) 541055346.

Authors a gree that this a rtic le rema in pemanently open access under the terms of the $\underline{\text { Creative Commons }}$ Attribution Lic ense 4.0 Intemational Lic ense 
again solely culturally meant for African men. A vast majority of these women are engaged in micro and informal enterprises. Anecdotal evidence suggests that only a few have found their way to managerial positions.

There have been several campaigns, laws, conventions, conferences to help give women equality at the workplace with the famous among them being the Beijing Conference. In spite of these campaigns for inclusion of women in top level management, anecdotal evidence further suggests the proportion of women in senior management positions is low as compared to men. Studies have shown men are two to three times more likely to be appointed to senior management positions than women. This has been attributed either to women's educational choices, their unwillingness to take challenging positions mainly because it would conflict with their socio-culturally assigned roles (performance of their reproductive and caring roles) or other reasons, which this study hoped to find out. Literature suggests in performing this productive roles, women face several challenges. For instance, most women are limited to occupations that are perceived as women's work trading, food vending, sewing, hairdressing among others as compared to men. More of these women are also found in the informal sector than men (United Nations, 2005), although only a few end up rising to managerial or top level management positions. Gender equality, despite being a well-established principle in international law and public policy, remains an indefinable ambition. According to the United Nations Development Programme's (UNDP) Human Development Report (1997), no society treats its women well as compared to its men. Gender inequality is one of the most pervasive inequalities which exists in all societies and cuts across social cleavages such as race, class and ethnicity. It also persists in the public and private spheres. Over thirty years after the United Nation's First World Conference on Women which outlined a plan of action to respond to the UN's goals of gender equality and the elimination of discrimination against women, concrete actions to achieve broad-based gender equality have been inadequate. Equal opportunity involves equal treatment of men and women at the workplace, with respect to equal remuneration as well as benefits for work of equal value and ensuring that employment policies and practices are free from all forms of genderbased discrimination. This also suggests that, gender sensitive employment procedures in addition to retention and positive recruitment of women to top managerial and executive positions as well as directorships of corporate bodies, must be embraced and implemented.

\section{LITERATURE REVIEW}

\section{Conventions and legislations on elimination of discrimination}

The doctrines on the elimination of all forms of discrimination against women are enshrined in one of the most comprehensive instruments adopted by the United Nations on the rights of women, that is, the Convention on the Elimination of All Forms of Discrimination against Women (CEDAW). CEDAW was adopted in 1979, by the UN as a means of using international efforts to protect and promote the rights of women in all nations. Even though the CEDAW came into force in September, 1981, it was ratified by Ghana in December 1986. In view of its ratification since December 1986, Ghana has been obliged under international human rights instrument such as the UN Chapter of the 1945 and Universal Declaration on Human Rights of 1948, Article 2 and the International Convention on Elimination of All Forms of Discrimination against Women (CEDAW) of 1997 to ensure that women are equally treated as their male counterparts in all aspects of life.

Article 1 of the CEDAW defines discrimination against women as "any distinction, exclusion or restriction made on the basis of sex which has the effect or purpose of impairing or nullifying the recognition, enjoyment or exercise by women, irrespective of their marital status, on a basis of equality of men and women, of human rights and fundamental freedoms in the political, economic, social, cultural, civil or any other field". Moreover, it is worth noting that, the definition of discrimination against women has no limitation and includes both intentional and unintentional discrimination, it also extends to all spheres of social, cultural, economic and political life. Also, the definition makes no distinction between public and private life of women, any differential treatment therefore, in any sphere of life that may give an advantageous right or privilege to a man over a woman may constitute discrimination as per article 1 of CEDAW. Upon ratification of the CEDAW by Ghana in December, 1986, some attempts have been made by the government to incorporate some of these principles in local legislations such as the Labour Act, 2003 (Act 651) as well as the 1992 Constitution.

In light of this, Article 12 of the 1992 Republican Constitution of Ghana guarantees every person the fundamental rights and freedoms, whereas Article 17 makes provision for the protection against discrimination and enjoins the State to take steps to end all forms of discrimination on the basis of gender, race, colour, ethnicity and creed as well as social and economic status. This notwithstanding, Article 35(5) (6) also enjoins the State to end all forms of discrimination through law reforms and affirmative actions.

Furthermore, there are both national and international laws which address the issue affecting particular segments of the population such as discrimination against women in all spheres of life.

Moreover, seeing education and training as a key element to the development of nations, it is prudent that corporate organisations and governments invest in the employment policies and programs that encourage the 
advancement of women at all levels and in all business sectors. This principle requires equal opportunities for formal and informal mentoring and networking as well as equal access to corporate supported education and training to men and women with the implementation of a business strategy for empowering women. That is, the principle will only be effective if policies and practices facilitating gender sensitive on women are encouraged by this principle. These policies to facilitate gender sensitive on women cannot permeate freely in certain parts of the continent due to cultural barriers, particularly in most Islamic states where elements of Sharia and family laws are believed to be incompatible with CEDAW.

According to the UN Global Compact on gender equality and empowerment of women, equality means business and the implementation of the principles of empowerment by governments and the corporate world at all levels of economic activities. Again, Articles 10 and 11, particularly, Article 11, reiterates the UN's commitment in ensuring equal opportunity for women in business and employment and seeks to affirm non-discrimination in education and employment and provides that States Parties shall take all appropriate measures to eliminate discrimination against women in the field of employment in order to ensure, on a basis of equality of men and women. The Article underlined certain specific rights which are indisputable to all human beings, these rights include:

(a) The right to work as an inalienable right of all human beings

(b) The right to the same employment opportunities, including the application of the same criteria for selection in matters of employment

(c) The right to free choice of profession and employment, which comprises the right to promotion, job security and all benefits and conditions of service and the right to receive vocational training and retraining, including apprenticeships, advanced vocational training and recurrent training

(d) The right to equal remuneration, including benefits, and to equal treatment in respect of work of equal value, as well as equality of treatment in the evaluation of the quality of work.

\section{United Nations Environment Program (2006)}

However, since its establishment in 1919, the ILO has also been dedicated to promoting the rights of all women and men at work and achieving equality between them. The ILO Policy on Gender Equality and Mainstreaming, which is made operational through the ILO Gender Equality Action Plan 2010-15, supports a two-pronged approach of gender mainstreaming and systematically analysing and addressing in all initiatives, the specific needs of both women and men, and targeted interventions to enable women and men to participate in, and benefit equally from development efforts.

The issue of gender equality has become a major concern in most international conferences and has eventually brought to light the fight against discrimination of women in all aspects of human endeavour. Notable among these conferences are the UN conferences on women, the 1985 Nairobi Forward Looking Strategies (NFLS), the 1995 Beijing Platform for Action and the 2000 review on Beijing commitments known as the Beijing +5 as well as other UN conferences and the Millennium Development Goal (MDGs) have clear provisions for improving the status of women and promoting gender equality.

\section{Women's inequality, globalisation and global governance}

While some women have benefited from increased participation in the formal workforce as a result of trade liberalisation, there is evidence that gender inequality is worsening (UN Research Institute for Social Development (UNRISD) report, 2005). Striving for Justice in an Unequal World, presents evidence that the prevailing neoliberal agenda, which underlies the current process of globalisation, has done little to promote gender equality, 15, and has often had an adverse impact on women.

\section{Gender discrimination and perception}

Even though the fight for gender equality has been one of the major discussions on most international conferences for some decades now, a recent research conducted in some top industries in Germany revealed an insignificant women representation at top level positions. For instance, some statistics showed that calls for a quota for women and the widely publicized appointment of four women to the executive boards of DAX 30 companies in 2011 still does not undermine the fact that women continue to play a marginal role in the most important economic and decision-making processes in Germany's largest companies (Holst and Schimeta, 2012).

The percentage of women in the prominent DAX 30 companies was 3.7 percent in 2011, which represents an increase of 1.5 percentage points from the previous year. In companies with government-owned shares some of which are considerably smaller such as 8.2 percent of executive board members and 17.7 percent of supervisory board members are women. This goes to prove that women are also far from achieving gender equality in the boardroom. In comparison with 2010, the percentage of exclusively male supervisory boards even significantly increased by 8.8 percentage points to 23.6 percent in 2011.

The growing realization among policy-makers, business, and civil society that greater gender diversification in the 
boardroom is needed has yet to lead to the breakthrough hoped for, in the appointment of women to executive and supervisory boards. Again, further studies in 2011 showed that, almost all seats on the executive boards of Germany's top 200 companies were held by men and out of a total of 942 positions on executive boards, only 28 positions were held by women. This is equivalent to three percent and shows that women on executive boards are still very much the exception. Among the companies ranked between 101 and 200 in order of turnover, only one executive board is chaired by a woman that is, almost 90 percent of the boards analyzed were exclusively male (Holst and Schimeta, 2012).

Gender roles and characteristics are cultured within multifaceted family relationships and become strengthened through the socialization process, where socially ascribed behaviour and responsibilities conform to the norms of each society (Chakravarti, 1995; Ball and Wilson, 2000; Karreman and Alvesson, 2001; Dick and Cassell, 2002). These socially created beliefs and expectations that people embrace about the roles of men and women in society are rarely neutral. They are rather essentially an outcome of power relations that characterize a society, where some are privileged while others may be suppressed or even marginalized. Again, these socially created beliefs further facilitate in creating occupational identities that are led by members of either gender. As a result, gender stereotypes permeate malefemale relationships influencing the ways in which members of each sex are expected to behave and the ways in which their behaviour is interpreted (Millward et al., 2000; Cohen and Huffman, 2003; Knights and Richards, 2003). In view of this, Acker $(1990,2006)$ argues that, gender at workplace lays emphasis on the processes that sustain the present circumstances on gender. Also he recounted that, at the organisational level, the processes are embodied within the construction of divisions, symbols and interactions between groups that result in gendered social structures and practices.

McDowell (1997) also argues that, to a large extent, women face work associated problems especially in cultures that promote masculine values and traits. This prevents them from being noticed, as well as perceiving themselves as fitting in the system (Knights and Richards, 2003; Katila and Merilainen, 2002; van Vianen and Fischer, 2002). In various studies conducted by Powell and Butterfield (1994) and Larwood et al. (1988), the results sustained that people may be involved in discriminatory behaviours and give justification for it, if the same is demonstrated by their superiors or those who have powers over their careers. However, Reskin (2000) cautions that gendering is an unconscious process and it is not necessarily based on overt opposition or hostility. Notwithstanding the fact that equality within the workplace has been reinforced through various types of regulations, discrimination against women continues to exist on several scopes that include occupation and economic gains (Fagenson, 1993). The prevalence of gender differences in the workplace influences recruitment, salary and career growth opportunities for women. Again, senior positions in organisations continue to be dominated by men despite a significant increase of women in managerial positions (Solomon, 1998; Burke and Nelson, 2002; Welting, 2003). On this note, Catalyst (2002) reiterated that, women would therefore continue to encounter barriers as a result of the culture and traditions of the organisation. Furthermore, Fagenson (1993) argues that the factors that are attributed to these differences include differences in education level and training genderrole socialization.

It has been noticed that, gender-based work behaviour differences are supposed to be much greater in male dominated professions such as the police and the armed forces as compared to other vocations like teaching, nursing which is believed also to be female dominated. Would it then be appropriate to believe that with larger numbers of women entering the police service where there is movement for equal opportunities, discrimination against women would decline? Gender discrimination according to Taylor and Ilgen (1981) and Scott (1994) is possible when women are often evaluated as less acceptable candidates for certain challenging jobs. Thus, they are unable to handle important or sensitive tasks effectively and are believed not to possess the necessary powers to achieve success in high status positions (Baden and Millward, 2000; Heilman, 1983).

Report of earlier studies by Marshal (1973) and Bell (1982) showed that policemen perceived women to be emotional, irrational, illogical and lacking in objectivity to handle the day-to-day unpleasantness of street policing. This was contended by Martin and Jurik (1996) and argued that male police officers associate women with social service, moral values, emotions and domestic roles and equate police with masculinity and build on the image of a 'masculine cop', to prevent the presence of women in the service. This to them was an opportunity to discriminate against women in the police service.

Gender equality thus refers to equality between men and women, and entails the concept that all human beings, both men and women, are free to develop their personal abilities and make choices without the limitations set by stereotypes, rigid gender roles and prejudices. Gender equality means that the different behaviour, aspirations and needs of women and men are considered, valued and favoured equally. It does not mean that women and men have to become the same, but that their rights, responsibilities and opportunities will not depend on whether they are born male or female. Gender equity also talks about fairness of treatment for women and men, according to their respective needs. This may include equal treatment or treatment that is different but which is considered equivalent in terms of rights, benefits, obligations and opportunities. According to Morris et al. (2005), there have been many high profile 
accusations of discrimination levelled against organisations within the last several years. For instance, it is argued that Morgan Stanley's investment banking business recently paid out $\$ 54$ million to over 300 female employees who claim to have been deprived of pay and promotions equal to those received by their male colleagues. Furthermore, according to statistics from the Equal Opportunities Commission [EOC] (2005), there has been no systematic decline over the last 12 years in the number of discrimination lawsuits filed, or the amount of monetary damages awarded to the plaintiffs of these suits.

Again, Ensher et al. (2001) argued that the implication of discrimination can extend beyond women's lack of access to formal and informal resources by influencing their experiences in, and perceptions of, their work environments. Many women who believe they have experienced discrimination, or have seen colleagues affected by it, illustrate less commitment in their work. Moreover, in a study conducted by Ensher et al. on employees across jobs and industries and among colleagues established that women and minority employees distinguished between three sources of discrimination, thus, supervisors, co-workers, and organisations. The more strongly employees believed that their supervisors discriminated against them because of their gender or that they had experienced organisational level discrimination, thus, the belief that organisational policies and practices were discriminatory, the less satisfied they were with their jobs and the less committed they were to the organisation. Also, in a study by Shaffer et al. (2000) the results showed that perceived gender-bias in organisational decision making has negative effects across cultures.

The more those female employees in the United States, Beijing, and Hong Kong believed they had experienced gender discrimination, the less satisfied they reported being with their jobs, and the less affectively committed they were to their organisations, and had stronger intentions to leave their jobs. In spite of all these conventions and laws ensuring gender equality at the workplace, it appears women are still discriminated against when it comes to appointments and promotions to top management positions and are often excluded during high level decision making process. This study, therefore, examined the impact of international conventions and local laws on gender equality, inclusion and non-discrimination of women at top management level in selected organisations in Ghana. It also examined the knowledge of top level management staff about international conventions and local laws on gender equality, inclusion and non-discrimination as well as barriers to managerial inclusion of women.

\section{Objectives of the study}

1. To examine knowledge of top level management about international conventions and local laws on gender equality, inclusions and non-discrimination.

2. To assess the impact of international conventions and local laws on gender equality, inclusion and non-discrimination of women in top level management positions.

3. To examine barriers to gender equality, inclusion and non-discrimination of women in top management level.

\section{Relevance of the study}

This study provides in depth information on issues of discrimination affecting women in top management positions in Ghana. It creates an awareness of the impact of the various regulations and conventions on gender discriminations and suggests other measures which could help facilitate equality amongst all sexes. The study identified factors, including culture, which contribute to the exclusion of women in top management positions. It also suggested the adoption of other means, other than regulation, which could reduce or eliminate certain barriers to the inclusion of women in top management positions.

This paper thus sets the stage for an open discourse on social, economic, political and academic platforms on issues concerning the exclusion of women in top management positions and its implications for the future of Ghana as a nation.

Policy makers would thus be equipped with relevant information which would guide them in the formulation of policies which may have implications for gender exclusion.

\section{METHOD}

\section{Research design}

A descriptive cross-sectional design was adopted for this study. According to Hair et al. (2003) and Neuman (2007), it is the most frequently used design in business research. Besides, Fraenkel and Wallen (2003) argued that the appropriateness of this design is based on the ability to lead the researcher to obtain in-depth information on the subject under study as well as drawing meaningful conclusions from the obtained data. Finally, descriptive cross-sectional survey also identifies standards or norms with which to compare present conditions in order to plan for the next step and to determine how to take action after having determined where you are and where you want to be.

\section{Participants, sample and procedure}

Participants included 160 respondents in top level management positions in organisations in the Greater Accra Region. The paper employed the Snowball sampling procedure to select 60 females and 100 males in top management positions from public and private institutions. This technique was deemed appropriate due to the difficulty of identifying a sampling frame for the study. Also, selfdeveloped questionnaire was used for the data collection exercise. The instrument was made up of three sections. Options were 
Table 1. Demographic Characteristics of the Study Sample $(N=160)$.

\begin{tabular}{llll}
\hline Variable & Description & Frequency & Percent \\
\hline \multirow{2}{*}{ Gender } & Male & 99 & 61.9 \\
& Female & 61 & 38.1 \\
Age & $>$ 49 years & 19 & \\
& 49 years & 64 & 11.9 \\
& $<49$ years & 77 & 48.0 \\
& & & \\
\multirow{4}{*}{ Marital Status } & Single & 19 & 11.9 \\
& Married & 125 & 78.1 \\
& Divorced & 13 & 8.1 \\
& Separated & 3 & 1.9 \\
& & & \\
Tenure & 1-4 years & 45 & 28.1 \\
& 5-10 years & 53 & 33.1 \\
& $>10$ years & 62 & 38.8 \\
\hline
\end{tabular}

Table 2. Independent t-test on awareness of existing conventions and laws.

\begin{tabular}{lccccc}
\hline Sex & $\mathbf{N}$ & Mean & Std. Dev & t & sig \\
\hline male & 36 & 3.06 & .814 & 2.406 & 0.018 \\
female & 38 & 3.47 & .742 & & \\
\hline
\end{tabular}

Source: Field Data, 2014.

provided to examine the demographic characteristics (ranging from gender to tenure) of the respondents. In the first part of the questionnaire, respondents were given a range of options (from institutional to educational) to select which option they perceive bars their inclusion to top management positions. In the second part, respondents' awareness of the existence of Conventions and Laws by gender was accessed by providing them two options (Aware, Not Aware). Finally, respondents were asked on what they perceive influences appointments and promotions in their respective organisations. The questionnaire was used because all the participants could read and write.

\section{Data analysis}

Data were analysed using descriptive statistics. Also, the independent t-test was used to determine the difference in the awareness of gender regualtions and laws between males and females. The Predictive analytical software (PASW) formerly known as the statistical package for the social sciences was used to analyse the data collected. Other trends and relationships were determined according to the responses to some of the items in the questionnaire.

\section{RESULTS AND DISCUSSION}

The participants' demographic characteristics are presented in frequency tables. The rationale for including demographic information is to indicate the composition of participants in order to have a better understanding of their responses and the result for this study. From Table 1 , a majority of the respondents $(61.9 \%)$ were males with only $38.1 \%$ representing females. Besides, the majority of the respondents $(40.0 \%)$ were 49 years and above, followed by $40.0 \%$ being 46 years of age whereas only $11.9 \%$ were less than 49 years old. For marital status, the majority of the participants $(78.1 \%)$ were married with only $1.9 \%$ separated or about to divorce. Finally, the length of service within the organisation was also assessed. From the responses gathered, a majority of the participants have worked for more than 10 years followed by $33.1 \%$ who have worked between the periods of 5 to 10 years. However, only $28.1 \%$ of them have worked within the period of 1 to 4 years.

\section{Knowledge of top level management about conventions and laws on gender equality, inclusions and non-discrimination}

The first objective of the study was on awareness of existence of conventions and laws on gender equality, inclusions and non-discrimination. The results in Table 2 show that the number of females (38) who are aware of the existence of conventions and laws on gender equality and non-discrimination is higher than the male's (36). Thus, the independentt-test analysis indicates that the difference in gender with respect to awareness of conventions and laws on gender equality is statistically significant $(t=2.406, p<0.05)$. To buttress this finding, the United Nations Environment Program [UNEP] (2006) on Gender Plan of Action stated that to secure high-level commitment towards gender equality requires top-level 
commitment from the leadership and management within organisations. Further, UNEP's Gender Plan of Action ensures that equality, equity and rights are well respected across gender, and especially across the top levels of management to promote equality of opportunity and treatment between women and men.

Besides, respondents were asked to indicate their awareness of some conventions and laws on gender equality and non-discrimination. The participants indicated their awareness of the following conventions and laws: (a) Convention on the Elimination of all forms of Discrimination Against Women (CEDAW); (b) International Labour Standards; (c) Beijing Conference Proceedings; (d) The 1992 Constitution of Ghana and (e) The Labour Act, 2003 (Act 651).

Impact of international conventions and local laws on gender equality, inclusion and non-discrimination of women in top level management positions

The second research objective looked at the impact of international conventions and local laws on issues of gender equality and non-discrimination of women in top level managerial positions. The findings of the study suggest non-consideration of conventions and laws during appointment and promotions. Thus, even though some respondents claimed to be aware of the existence of international conventions and local legislations on gender equality and non-discrimination, it appears recruitment and appointment to top management positions do not take into consideration these regulations and as such do not often allow fair representation of men and women. Notwithstanding the fact that equality within the workplace has been reinforced through various types of regulations, Fagenson (1993) argued that discrimination against women continues to exist on several scopes that include occupation and economic gains. Fagenson further suggested that the existence of gender differences in the workplace influences recruitment, salary structure and career growth opportunities for women. In the Ghanaian situation for instance, nonrepresentation of women in top management positions is seen in almost all sectors, particularly in the political arena as well as in certain public institutions. Currently, the Ghanaian Parliament has only 29 women parliamentarians out of a total of 275 . The Judicial Council of Ghana currently also has only 5 members out of a total of 18. Even though there appears to be low women representation in top management positions in Ghana, there seems to be some strides made within certain public institutions, such as the judicial service where the Chief Justice is currently a woman. The parliamentary service of Ghana also had a woman speaker from $7^{\text {th }}$ January 2009 to $6^{\text {th }}$ January 2013.Thus, in as much as more needs to be done in ensuring a lot more women representation in top management positions, there appears to be some progress, particularly, within the public sector (Akpah, 2013; Judicial Service of Ghana, 2014; Parliamentary Service of Ghana, 2014).

However, data gathered indicate that even where considerations are given during appointments and promotions, the focus has always been on qualification, years of service in an organisation and position in the organisation for the public sector institutions whereas the private sector focuses mainly on loyalty and family relations, and political affiliations. Hence, gender balance, experience and/or competence are often relegated to the background. Participant responses on the factors that influence appointment and promotion of top level management are illustrated in Figure 1.

\section{Barriers to inclusion of women in top management level}

The third research objective sought to establish the barriers to inclusion of women in top level management positions. As shown in Table 3, institutional and cultural barriers respectively, recorded the highest response rate from the participants. Thus, Catalyst (2002) opined that, women would continue to encounter barriers as a result of the culture and traditions of the organisation in which they find themselves. According to Fagenson (1993), these barriers are caused by differences in educational level and training, and gender-role socialization. However, intimidation from male counterparts was the least barrier to women's inclusion in top management positions. In agreement with this finding is the assertion that senior positions in organisations continue to be dominated by men despite a significant increase of women in managerial positions (Solomon, 1998; Burke and Nelson, 2002; Welting, 2003).

\section{CONCLUSION AND RECOMMENDATIONS}

Understanding the significance of international conventions and local laws on gender issues in Ghana is imperative. Consistent with this proposition, the study provides insight into the impact of international conventions and local laws on gender equality, inclusion and non-discrimination at top level management in Ghana. Nevertheless, the study revealed that most people in top level management are unaware of international conventions and local laws on gender equality, inclusion and non-discrimination. Finally, it was found that institutional, intimidation from male colleagues, social, cultural and educational issues were among the barriers to gender equality, inclusion and non-discrimination of women in top management level.

A key recommendation is that if these barriers are addressed, it would not only ensure full participation of women in the growth and development of the private 


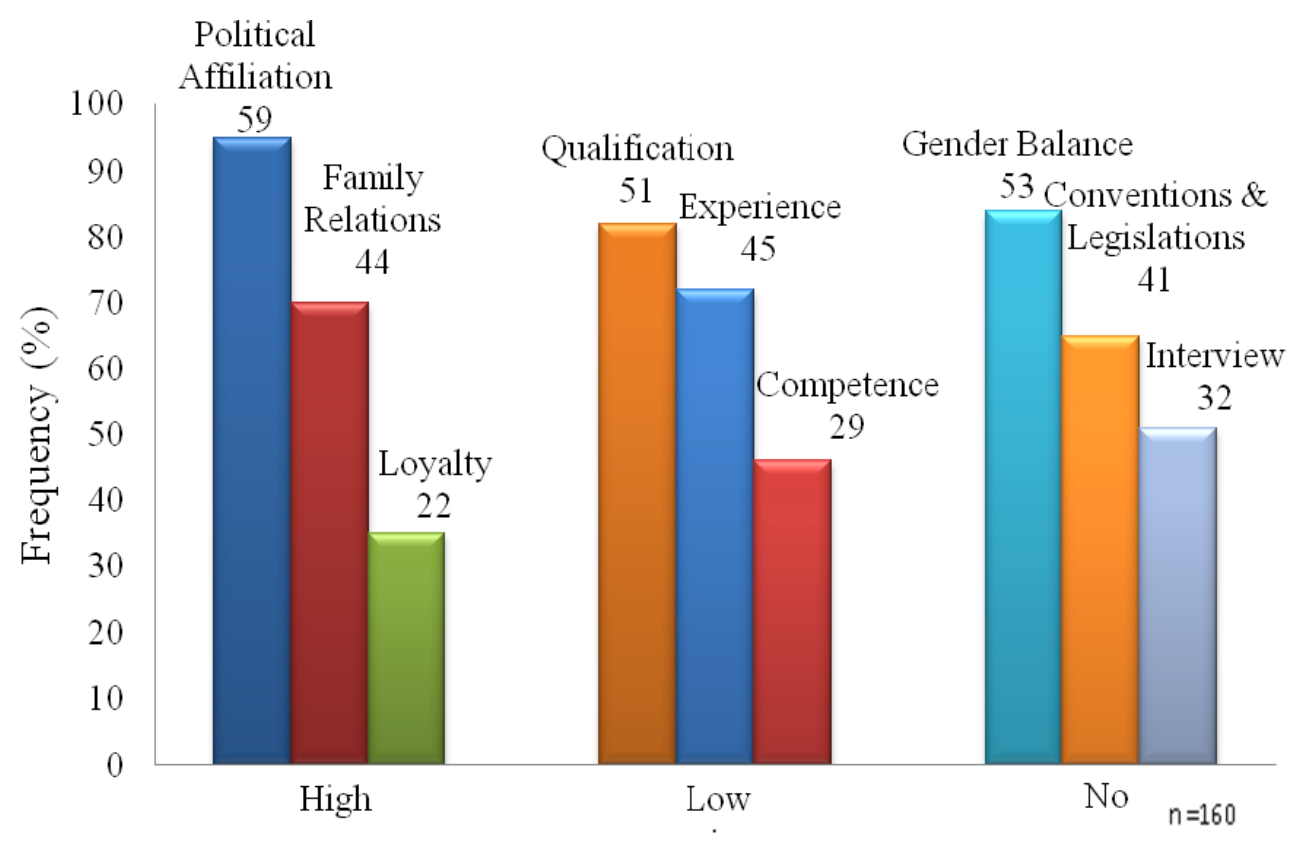

Figure 1: Factors influencing appointments and promotions.

Table 3. Barriers to Women's Inclusion in Top Management

\begin{tabular}{lcccccc}
\hline Barriers & \multicolumn{2}{c}{ Female } & \multicolumn{2}{c}{ Male } & \multicolumn{2}{c}{ Total } \\
\hline & Freq. & $\%$ & Freq. & $\%$ & Freq. & $\%$ \\
\hline Institutional & 60 & 100 & 80 & 80 & 140 & 88 \\
Intimidation from male & 20 & 33 & 61 & 61 & 81 & 51 \\
Social & 37 & 62 & 22 & 22 & 40 & 25 \\
Cultural & 54 & 90 & 30 & 30 & 84 & 53 \\
Educational & 34 & 62 & 15 & 15 & 52 & 33 \\
\hline
\end{tabular}

Note. Total response exceeds $100 \%$ because of multiple response items.

sector but also the public sector economy. To ensure the fruition of this economic growth and development agenda, rigorous policy and programme interventions like in-service training, seminars and workshops to make the conventions and laws more effective than they are currently should be employed to fully utilize the potential of women. The Ministry of Gender and Social Protection, Civil societies, and religious bodies are implored to take up these recommendations to aid address this unfortunate situation.

\section{Conflict of Interests}

The authors have not declared any conflict of interests.

\section{REFERENCES}

Acker J (1990). Hierarchies, jobs, and bodies: A theory of gendered organisations. Gender Soc. 4:139-158.
Acker J (2006). Inequality regimes: Gender, class and race in organisations. Gender Soc. 20(4):441-464.

Akpah P (2013).List of the 29 Women in Parliament, Retrieved, June 2014 from http://www.spyghana.com/list-of-the-29-women-in-ghanasparliament/

Baden S, Millward K (2000).Gender inequality and poverty: Trends, linkages, analysis and policy implications. BRIDGE (Unpublished Report).

Ball K, Wilson DC (2000). Power, control and computer-based performance monitoring: Repertoires, resistance and subjectivities.Organisation Stud. 21(3):539-565.

Bell DE (1982). Regret in decision making under uncertainty. Oper. Res. 5:960-981.

Burk R, Nelson DL (2002).Advancing women's careers: Research and practice. London: Blackwell.

Catalyst (2002).Women in leadership-European business imperative. New York, NY: Catalyst.

Chakravarti U (1995). Gender, caste and labour: Ideological and material structure of widowhood. Econ. Polit. Weekly 30(36):22482256.

Cohen PN, Huffman ML (2003). Individuals, jobs, and labour markets: The devaluation of women's work. Ameri. Sociolog. Rev.68, 443-463.

Dick P, Cassell C (2002). Barriers to managing diversity in a UK police constabulary: The role of discourse. J.Manage. Stud. 39 (7), 953-976.

Ensher EA, Grant-Vallone EJ, Donaldson SI (2001). Effects of 
perceived discrimination on job satisfaction, organisational commitment, organisational citizenship behaviour, and grievances. Human Resourc. Dev. Q. 12:53-72.

Equal Opportunities Commission (EOC) (2005). It's time to get even. Manchester: EOC.

Fagenson EA (1993). Women in management: Trends, issues, and challenges in managerial diversity (Women and Work: A research and policy series). London: Sage Publications, Inc.

Fraenkel JR, Wallen N.E (2003). How to design and evaluate research in education (5th ed.). Boston, MA: McGraw-Hill.

Hair JF, Babin B, Money AH, Samouel P (2003). Essentials of business research methods. Hoboken: Wiley.

Heilman ME (1983). Sex bias in work settings: The lack of fit model. In L.L. Cummings \& B.M. Staw (Eds.), Research in organisational behaviour (vol. 5, pp.269-298). Greenwich, CT: JAI.

Holst E, Schimeta J (2012). Top-level management in large companies: Persistent male-dominated structures leave little room for women. DIW Economic Bulletin 4.Retrieved, July 22, 2013, from http://www.diw.de/sixcms/detail.php?id=diw_01.c.396480.de.

Judicial Service of Ghana (2014).Judicial Council, The Judiciary, Retrieved, June 2014, from http://www.judicial.gov.gh/index.php/judicial-council.

Karreman D, Alvesson M (2001).Making newsmakers: Conversational identity at work. Organisation Stud. 22(1):59-89.

Katila S, Merilainen S (2002). Metamorphosis: From "nice girls" to "nice bitches": Resisting patriarchal articulations of professional identity. Gender Work Organ. 9(3):336-354.

Knights D, Richards W (2003). Sex discrimination in UK academia. Gender Work Organ. 10(2):213-238.

Larwood L, Szwajkowski E, Rose S (1988). Sex and race discrimination resulting from manager-client relationships: Applying the rational bias theory of managerial discrimination. Sex Roles 18:929.

Martin SE, Juri NC (1996). Doing justice, doing gender: Women in law and criminal justice occupations. Thousand Oaks, CA: Sage.

McDowell L (1997). Capital culture: Gender at work in the city. Oxford: Blackwell.

Millward N, Forth J, Bryson A (2000).All change at work: British employment relations $1980-1998$, as portrayed by the workplace (Industrial Relation Survey Series). London: Routledge.

Morris EP, Stewart SH, Ham L (2005). The relationship between social anxiety disorder and alcohol use disorders: A critical review. Clin. Psychol. Rev. 25:734-760.

Neuman WL (2007). Basics of social research: Qualitative and quantitative approaches ( $2^{\text {nd }} e d$. $)$. Boston: Pearson Education Inc.
Parliamentary of Ghana (2014). Office of Speaker, Parliament of Ghana, $\quad$ Retrieved,June 2014 from http://www.parliament.gh/content/433/41.

Powell G, Butterfield D (1994).Investigating the "glass ceiling" phenomenon: An empirical study of actual promotions to top management. Acad. Manage. J. 37:68-86.

Reskin BF (2000). The proximate causes of employment discrimination. Contemp. Sociol. 29:319-328.

Scott AM (1994). Gender segregation and social change. Oxford: Oxford University Press.

Shaffer MA, Joplin JRW, Bell MP, Lau T, Oguz C (2000). Gender discrimination and job-related outcomes: A cross-cultural comparison of working women in the United States and China. J. Vocat. Behav. 57:395-427.

Solomon, C.M. 1998. 'Women Are Still Undervalued:Bridge the Parity Gap', Workforce 77(5):46-53.

Taylor MS, Ilgen DR (1981). Sex discrimination against women in initial placement decisions: A laboratory investigation. Acad. Manage. J. 24(4):859-865.

Tuyizere AP (2007). Gender and development: The role of religion and culture. Kampala: Makerere University.

United Nations (2005).Violence against disabled children. New York: United Nations.

United Nations Development Programme [UNDP] (1997). Human development report 1997. New York: Oxford University Press.

United Nations Environment Program (2006).Global gender policy series: UNEP's gender plan of action. New York: IUCN Gender Office.

vanVianen AEM, Fischer AH (2002). Illuminating the glass ceiling: The role of organisational culture preferences.J. Occupat. Organ. Psychol. 75:315-337.

Wentling RM (2003). 'The Career Development ofWomen in Management', Women in Manage. Rev. 18(6):311-324. 